\title{
Use of thermography in diagnosing and predicting defects in structural components of machines and devices
}

\author{
Zastosowanie termografii w diagnozowaniu i przewidywaniu \\ uszkodzeń w elementach konstrukcyjnych maszyn i urządzeń
}

\section{ANDRZEJ SUCHETA KRZYSZTOF SIKORA *}

The use of passive thermography to diagnose defects in the connection of ribs with tubes in convection heaters, has been reported, as well as the use of thermal imaging cameras to predict the occurrence of breakage of a structural element subjected to tensile stress.

KEYWORDS: passive thermography, thermal imaging

In most technological processes and during the operation of the equipment, we deal with the transformation of energy, which is accompanied by the heat flow, causing changes in the temperature of the individual components of the device. Observations of surface temperature distribution allow to assess the intensity of the process. Local elevation of the surface temperature to the expected value may mean that the process is not proceeding correctly $[1,5]$.

Due to thermal imaging cameras and the ability to record infrared radiation objects, thermography has been used in many fields. Non-contact temperature measurement allows Non-Destructive Testing (NDT) of materials and equipment.

In many papers, methods using active thermography, which stimulate the object under investigation with a pulse (usually thermal), and then record temperature changes over time and analyze the distributions obtained, are described [2-4]. Less commonly described are methods that utilize passive thermography, i.e. recording the temperature distribution on the surface of the object during normal operation, without external forces. These methods are simpler, because they do not require the use of additional thermal induction devices, but they also have limitations resulting, among others, from the rapid equalization of temperature fields in objects. Passive methods are already a standard in diagnostics in the power industry and in evaluating the correctness of thermal insulation. Other areas, in which passive thermography can be successfully applied, are also presented in the paper.

Application of passive thermography in convection heater diagnostics

For efficient operation of convection heaters, it is necessary to intensify heat exchange by minimizing thermal resistance. The use of highly conductive

\footnotetext{
* Dr hab. inż. Andrzej Sucheta, prof. ATH (sucheta@ath.bielsko.pl); dr inż. Krzysztof Sikora (ksikora@ath.bielsko.pl) - Akademia Techniczno-Humanistyczna w Bielsku-Białej
}

\author{
DOI: https://doi.org/10.17814/mechanik.2017.11.186
}

materials such as copper or aluminum minimizes thermal conductivity, but it is also necessary to minimize the contact resistance on the rib and tube connections, through which the heating medium flows. One method of joining is to apply ribs to tubes with holes that are only slightly larger than the outer diameter of the tube and then increase the diameter of the tube by mechanical means (by rolling or pulling). There is a risk that, during this process, all ribs will not be properly adhered to the tube (due to inaccuracy in their performance) - resulting in a thermal contact resistance, which decreases the heat output of the heater.

The use of thermal imaging cameras allows to observe possible differences in the temperature of individual ribs and to detect mounting errors.

Fig. 1 shows an example of a convection heater in the duct.

The heater was supplied with $45{ }^{\circ} \mathrm{C}$ water and a film was recorded using the Flir E50 thermal imaging camera to show heating of the radiator and the ribs.

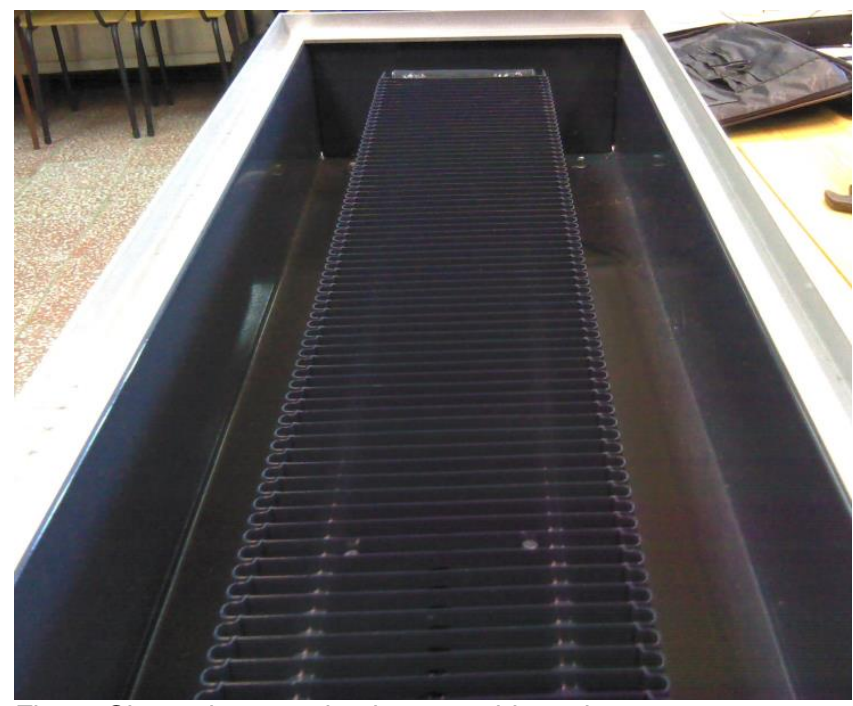

Fig. 1. Channel convection heater subjected to tests

Several places have been identified that indicate a greater contact resistance (for a worse connection of the tube to the rib). Measurement points Sp1 and Sp2 (fig 2) were placed on two adjacent ribs. The heating element first flows into the rib with $S p 1$, and then to the rib with $S p 2$, thus the temperature of the first rib should be higher than the second. On the basis of the measurement, it 
can be stated that the temperature of the first rib is about $2^{\circ} \mathrm{C}$ lower than the second, which means that its contact resistance is greater and the rib is less conducive to heat. Repeatedly made measurements confirmed previous observations.

Diagnosis of radiators can be carried out not only in the laboratory or in the assembly hall, but also in the place where the radiator operates. During operation of the heater, the contact points are subject to varying thermal loads and, in extreme cases, loosening of the rib may occur, which results in a significant reduction in the heat output. Such situations can be very easily diagnosed using a thermal imager.

In fig. 3 , it can be seen that some ribs in the heater have lower temperature also during steady state operation. The highest temperature is at Sp3. Taking into account the flow direction of the heating medium inside the tube, to which the ribs are attached, the ribs should have lower temperature. The Sp1 measuring point has lower temperature than the other rib with Sp2, which means that the ribs are worse mounted (greater thermal resistance).

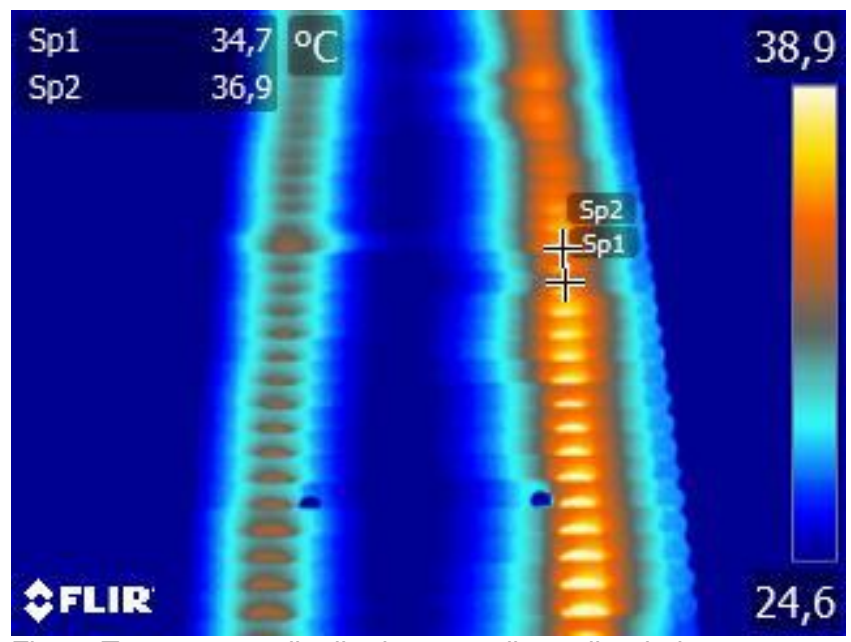

Fig. 2. Temperature distribution on radiator ribs during warm-up. Sp1 and Sp2 - temperature measurement points

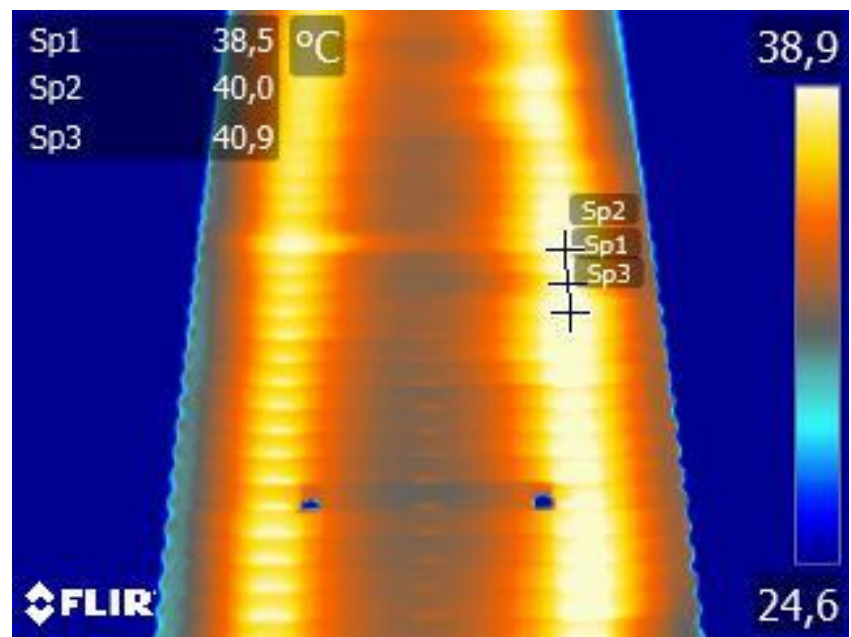

Fig. 3. Temperature distribution on radiator ribs in steady state

\section{Use of thermography to predict break points for stretched elements}

Passive thermography can also be used to predict damage locations in load-bearing components. During deformation of the material, some of deformation energy is converted to heat and causes a local increase in temperature at the mechanical energy dissipation point. The case of stretching of the structural component at the MTS station has been analyzed.

Fig. 4 shows the position of linear actuator MTS, where the experiment of stretching a sample of S235JR steel with a length of $250 \mathrm{~mm}$, width of $10 \mathrm{~mm}$ and thickness of $1 \mathrm{~mm}$ (fig. 5), was carried out. The samples were covered with a soot layer to increase the surface emissivity.

Samples were fixed in an MTS (fig. 6), a constant feedrate of $5 \mathrm{~mm} / \mathrm{min}$ was set and a stretch test was performed. After about 10 seconds of stretching, a slightly warmer area appeared on samples (fig. 7).

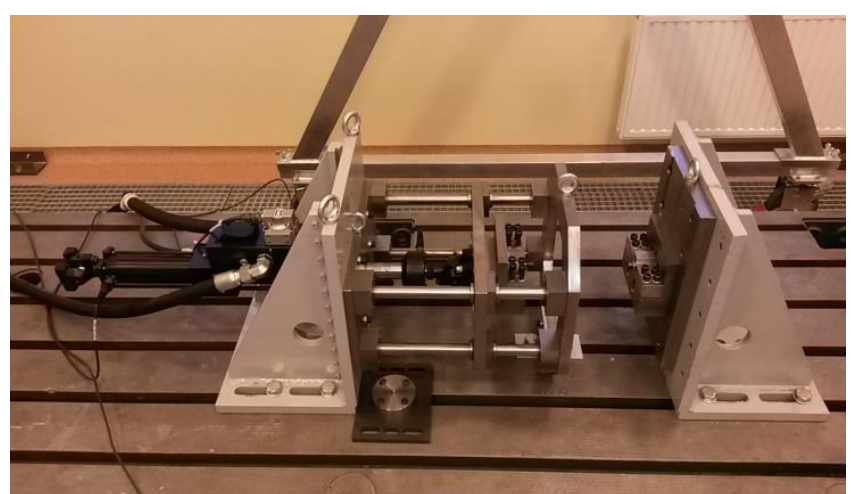

Fig. 4. Stretching station for samples

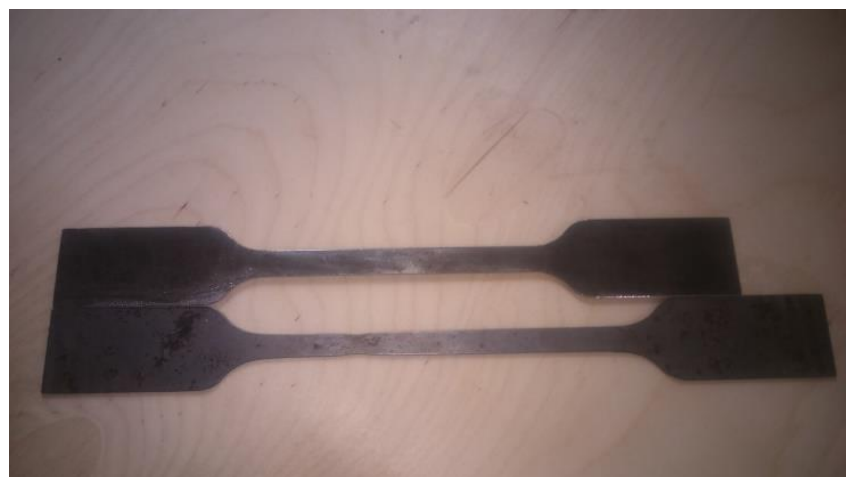

Fig. 5. Not damaged sample (above) and after stretch (below)

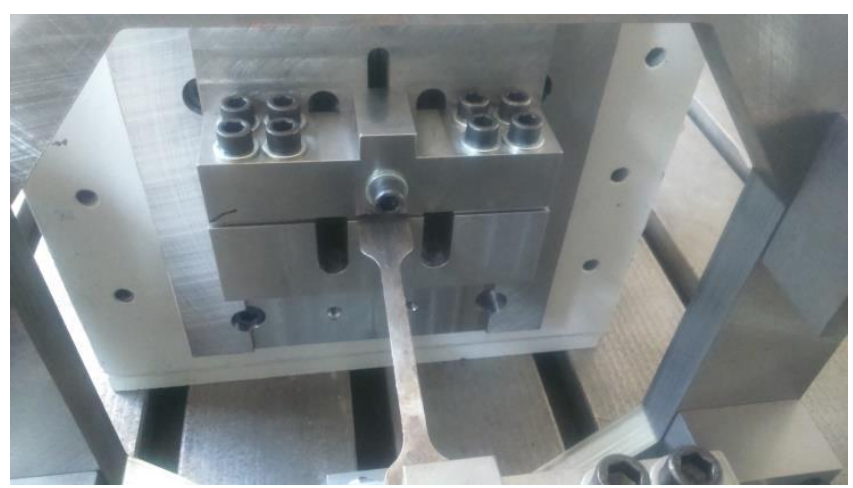

Fig. 6. Sample mounted on a bench

After about 40 seconds, the area of elevated temperature is clearly visible (fig. 8). The breaking moment was after $7 \mathrm{~min}$ and $43 \mathrm{~s}$ of stretching the sample (fig. 9). The sample breaking point corresponded to the place, where the initial temperature change occurred, which could be recorded after $10 \mathrm{~s}$ of stretching. 
Fig. 10 shows the power-displacement graph with the points, where records using thermal imaging cameras were taken: $P 1$ is the point corresponding to fig. $7, P 2$ corresponds to fig. 8, while $P 3$ corresponds to fig. 9 .

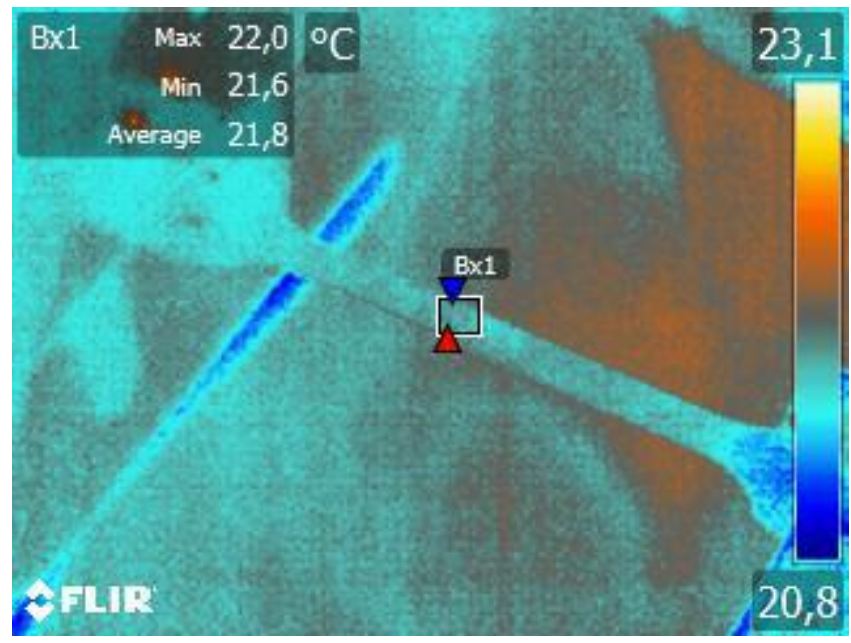

Fig. 7. Thermogram after $10 \mathrm{~s}$ of stretching

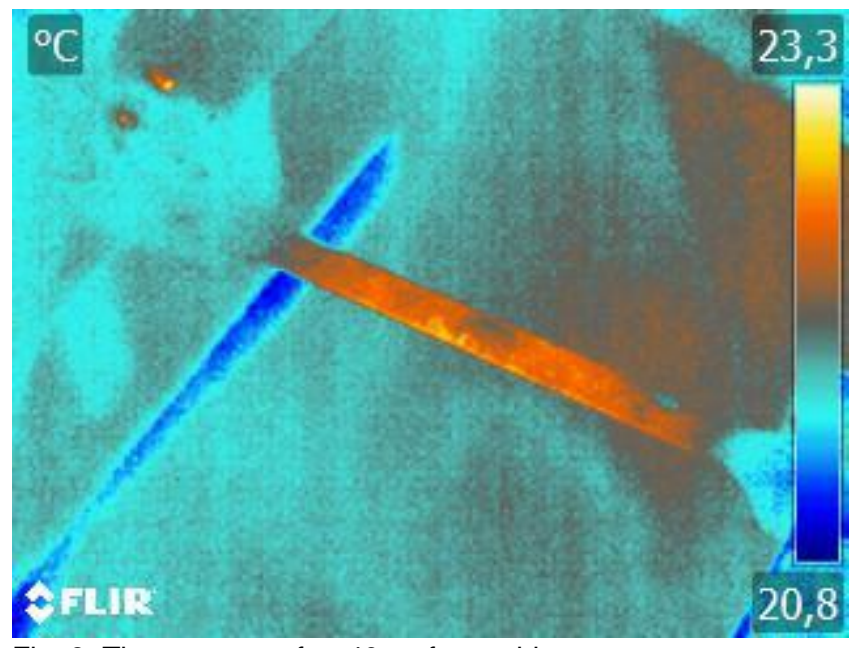

Fig. 8. Thermogram after $40 \mathrm{~s}$ of stretching

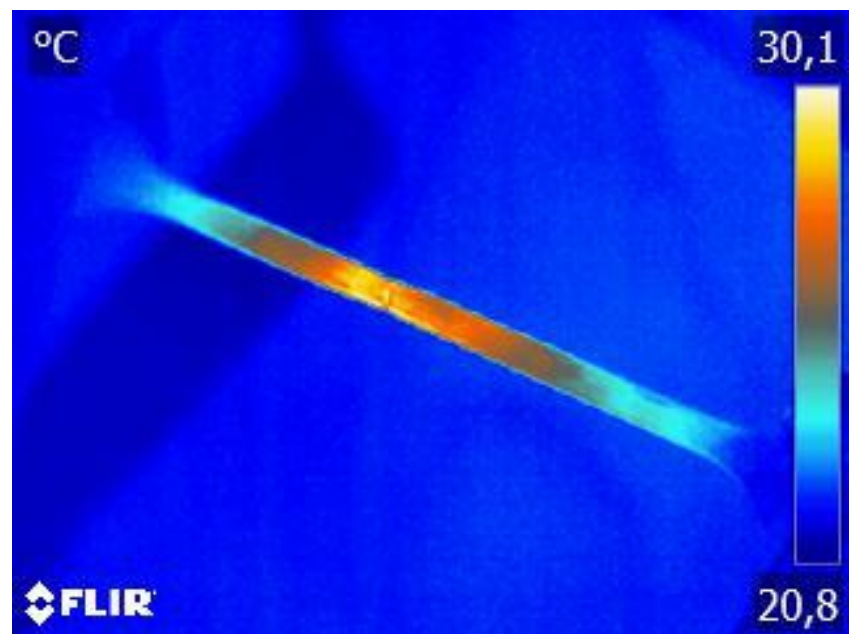

Fig. 9. Thermogram after $7 \mathrm{~min}$ and $43 \mathrm{~s}$ of stretching at the moment of sample breaking

For subsequent stretched sample, very similar results were obtained. This allows to formulate the proposition that passive thermography can be used to predict, where damage occurs in structural components based on the heat generated at these locations and the resulting temperature increase.

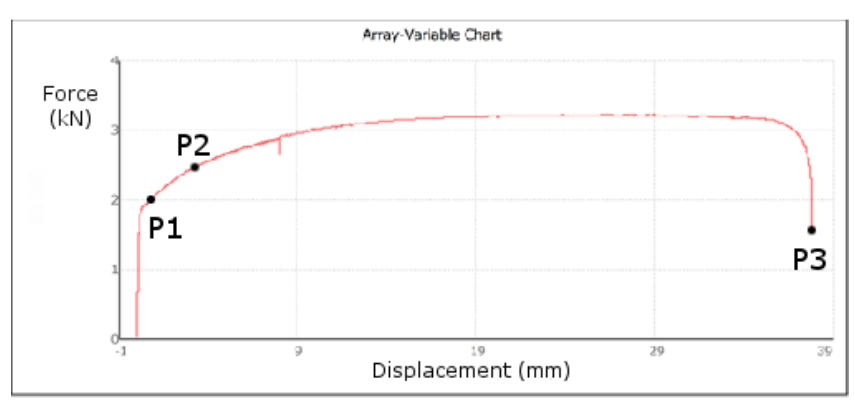

Largest force $3.215 \mathrm{kN}$

Fig. 10. Diagram with marked points of thermogram execution

Of course, this diagnostic can only be considered in terms of quality - it does not give information about the degree of damage or the anticipated time to destroy the element.

\section{Conclusions}

Passive thermography is successfully used in power engineering (for quick diagnostics of electrical installations, fuses, power transmission lines) or construction (for detection of thermal insulation damage, thermal bridges, wall humidity and floor heating systems). It is used in medicine (for diagnosing inflammatory conditions or cancerous lesions). Thermal imaging systems have long been used by the military and other uniformed services. Due to the decreasing prices of thermal imaging cameras and simplification of their design (and hence easier handling), thermovision can also find a wider use in the rapid diagnostics of machine elements and equipment in various fields of industry. However, passive thermography only allows for quality diagnostics.

In order to find the cause of changes observed, further research or analysis is required. For a convection heater, a mathematical model of heat flow should be constructed, in which the contact resistance between the tube and the rib is the parameter. The numerical value of this parameter will be the solution of the inverse heat conduction problem.

Also, the observation of the local increase in temperature of the structural element may be just a premise for further diagnosis.

\section{REFERENCES}

1. Oliferuk W. „Termografia podczerwieni w nieniszczących badaniach materiałów i urządzeń". Biuro Gamma, 2008.

2. Madej J. „Lokalizacja uszkodzeń metodą termiczną" IV Międzynarodowe Sympozjum Mechaniki Zniszczenia Materiałów $i$ Konstrukcji, Augustów 2007.

3. Uhl T. "Termografia dynamiczna jako narzędzie diagnostyki konstrukcji”. Zeszyty Naukowe Politechniki Rzeszowskiej. Budownictwo i Inżynieria Środowiska. 45 (2007): s. 157-171.

4. Szczepanik M., Stabik J., Wróbel G., Wierzbicki Ł. „Wykorzystanie systemów termowizyjnych do badań materiałów polimerowych". Modelowanie Inżynierskie. 36 (2008): s. 279-286.

5. Wernik J., Wołosz K.J. Grabowski M "Numerical and thermography study of heat conduction through the finned motor housing". DOI: 10.17814/mechanik.2015.7.326. 